
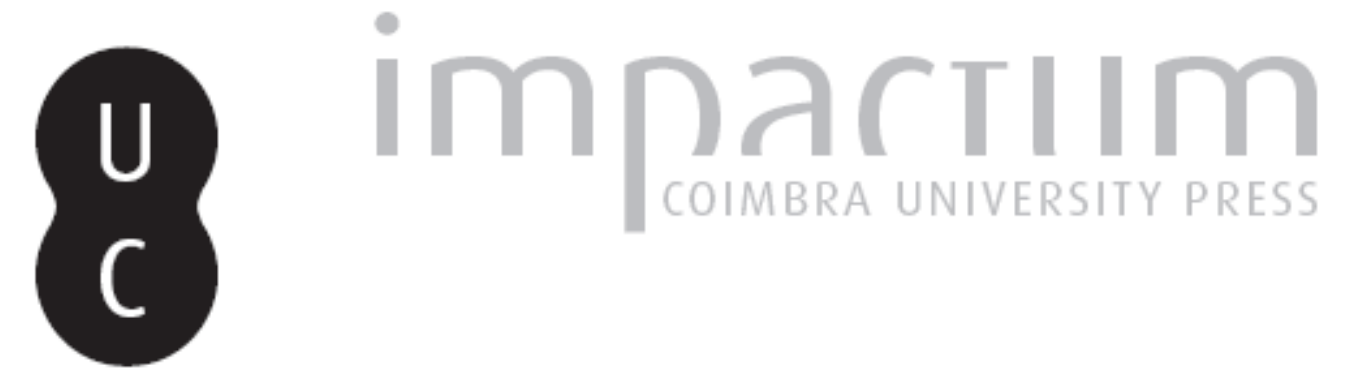

\title{
Os «barris ibéricos» de Portugal
}

Autor(es): $\quad$ Gamito, Teresa Júdice

Publicado por: Imprensa da Universidade de Coimbra

URL persistente:

URI:http://hdl.handle.net/10316.2/45697

DOI:

DOI:https://dx.doi.org/10.14195/1647-8657_22_2

Accessed : $\quad$ 26-Apr-2023 10:54:57

A navegação consulta e descarregamento dos títulos inseridos nas Bibliotecas Digitais UC Digitalis, UC Pombalina e UC Impactum, pressupõem a aceitação plena e sem reservas dos Termos e Condições de Uso destas Bibliotecas Digitais, disponíveis em https://digitalis.uc.pt/pt-pt/termos.

Conforme exposto nos referidos Termos e Condições de Uso, o descarregamento de títulos de acesso restrito requer uma licença válida de autorização devendo o utilizador aceder ao(s) documento(s) a partir de um endereço de IP da instituição detentora da supramencionada licença.

Ao utilizador é apenas permitido o descarregamento para uso pessoal, pelo que o emprego do(s) título(s) descarregado(s) para outro fim, designadamente comercial, carece de autorização do respetivo autor ou editor da obra.

Na medida em que todas as obras da UC Digitalis se encontram protegidas pelo Código do Direito de Autor e Direitos Conexos e demais legislação aplicável, toda a cópia, parcial ou total, deste documento, nos casos em que é legalmente admitida, deverá conter ou fazer-se acompanhar por este aviso.

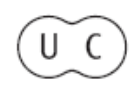


FACULDADE DE LETRAS

INSTITUTO DE ARQUEOLOGIA

\section{CONIMBRIGA}

VOLUMEXXII

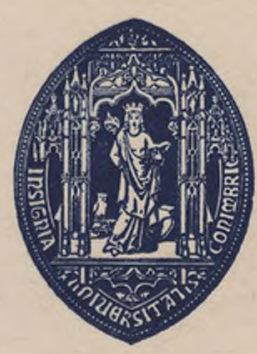

UNIVERSIDADE DE COIMBRA

1983 


\section{TERESA Júdice Gamito}

Assistente da Universidade do Algarve

Bolseira da Fundação Calouste Gulbenkian

OS «BARRIS IBÉRICOS» DE PORTUGAL

«Conimbriga», XXII, 1983, p. 195-208

RESUMO: Existem apenas duas áreas de dispersão dos «barris ibéricos»:

uma nos arredores de Valência, na costa sul de Espanha, e outra no interior do sudoeste peninsular, mais concretamente no interior do Alentejo e na província espanhola da Estremadura. Este curioso tipo de vaso foi estudado sobretudo por Fletcher Valls (1957), que apresentou então a sua tipología.

O Mapa 1 apresenta a distribuição das ocorrências deste tipo de vaso e o número de referência dos povoados. Os exemplares portugueses, com excepção do de Santa Olaia (Santos Rocha, 1908, figs 1 e 2) estavam ainda por publicar. O exemplar do Castro de Segóvia, Eivas (figs. 3 e 4) foi encontrado durante as escavações de 1972, num estrato bem definido correspondente a um contexto cultural 'ibérico' e ao $2 .^{\circ}$ estrato de ocupação da Idade do Ferro II (Júdice Gamito, 1981, 1980a, 1979). Colocamo-lo no n. 3 da tipologia de Fletcher. O barril de Vaiamonte, Monforte (figs. 5 e 6) foi encontrado durante as escavações do Prof. Heleno nos anos 50, estando ainda por publicar, tal como o exemplar da Azougada, Moura (fig. 7), mas pertencendo igualmente a contextos 'ibéricos'.

Discute-se seguidamente este tipo de cerâmica sendo de recusar a possibilidade de uma difusão directa através de povos fixades na costa oriental da Península Ibérica (Santob Rocha, 1908; Siret, 1893) ou mesmo de um modelo exportado, pele mesma via, para o interior (Hernandez, 1979; Fletcher, 1957).

Embora os contactos entre os povos da costa e do interior fossem frequentes desde o Neolítico, não há indícios de um centro produtor. Por outro lado, a grande diversidade de formas levam-nos antes a pensar numa resposta semelhante ao mesmo tipo de ambiente extremamente seco e quente, que um barril de barro rodeado por um sistema de suspensão de cordas oferecia, ocorrendo em contextos caracterizadamente 'ibéricos' dos séculos v e iv a.C. 
Abstract: There are only two main scattering areas for the 'Iberian' clay casks: one around Valencia on the southern coast of Spain, the other in the inland c-f southwest Iberia, the Spanish province of Estremadura and the Portuguese Alentejo. This curious pottery vessel was studied by Fletcher Vails (1957), who first presented a typology for the 'Iberian' clay casks.

Map 1 shows the dispersal areas of this kind of pottery and the reference number of the settlement sites. The Portuguese examples, with exception of Santa Olaia one (Santos Rocha, 1908, figs. 1 and 2) were still unpublished. Castro de Segovia (Elvas) cask (figs. 3 and 4) was found during the excavations of 1972 in a well defined and limited 'Iberian' stratigraphic context corresponding to the Late Iron Age occupation layer (Júdice Gamito, 1981, 1980a, 1979). We place it in n. 3 of Fletcher's typology. Cabeço de Vaiamonte (Monforte) cask fragment (figs. 5 and 6) was found during Prof. Heleno's excavations in the early $50 \mathrm{~s}$, corresponding perhaps to n. 2 of Fletcher's typology, was not published as well as the Azougada (Moura) one (fig. 7).

The occurence of this type of pottery is then discussed being rejected the possibility of a direct difusion through peoples settled in the eastern coast of Iberia (Santos Rocha, 1908; Siret, 1893) or the idea of a vessel brought through the same via and exported inland (partly defended by Fletcher, 1957 and Hernandez, 1979). Although contacts between these two areas were possibly constant since the Neolithic, there are no signs of a production centre. The variety of forms lead us think rather of a similar answer to an extreme dry and hot environment which a clay cask surrounded by a rope hanging system could offer, and their occurence in coherent 'Iberian' contexts dated from the 5th and 4th Centuries B.C. 


\section{OS «BARRIS IBÉRICOS» DE PORTUGAL}

As reduzidas áreas de dispersão deste tipo de recipiente bem como a sua diversidade de aspecto, dentro de urna forma básica comum (Fletcher Vails, 1957), torna-o particularmente interessante. Com excepção do barril de Santa Olaia, publicado por Santos Rocha (Santos Rocha, 1908), os outros três exemplares encontrados em Portugal, até este momento, apresentam-se ainda inéditos, surgindo numa área afim da Estremadura espanhola, no interior do Alentejo, mais exactamente no Castro de Segovia (Elvas), no Cabeço de Vaiamonte (Monforte) e no Castro da Azougada (Moura).

A Península Ibérica apresenta apenas duas áreas de dispersão deste tipo de vaso: o Sudeste espanhol, nos arredores de Múrcia, Alicante, e particularmente incisiva em Valência, e nas províncias de Cáceres e Badajoz, em cujo grupo poderemos incluir os nossos barris alentejanos. Além destas duas áreas de ocorrência observam-se ainda dois casos isolados: um no extremo nordeste da província de Valência, perto de Lérida, e o outro na costa atlântica, francamente mais afastado das duas áreas referidas, no Castro de Santa Olaia.

O Mapa 1 apresenta a ocorrência destes recipientes já publicados em Espanha (Hernandez, 1979, Nordstrom, 1967, Fletcher Vails, 1957, entre outros) acrescidos dos exempleres portugueses, devendo-se salientar o caso de La Bastida de los Alcuses, Mogente (Valencia) onde foram encontrados 28 exemplares, provenientes das escavações ali efectuadas em 1928, pelo Servicio de Investigación Prehistórica de Valencia, dos quais já alguns exemplares tinham sido publicados por Ballester Tormo e Pericot Garcia (Ballester Tormo et alii 1928), mas todo o conjunto somente publicado por 
Fletcher Vails (Fletcher Vails, 1975), que foi quem de facto chamou a atenção para este tipo peculiar de cei àrnica, apresentando a sua tipologia em 1957. Os exemplares descritos por Fletchei Valls foram encontrados nos seguintes povoados:

\begin{tabular}{|c|c|c|c|}
\hline 1 - El Castillico (Fortuna, Múrcia) & \multicolumn{3}{|c|}{-2 exemplares } \\
\hline 2 - San Anton (Orihuela, Alicante) & - & 2 & $»$ \\
\hline 3 - La Albufereta (Alicante) & - & 2 & $»$ \\
\hline 4 - La Serreta (Alcoy, Alicante) & - & 2 & $»$ \\
\hline 5 - El Puntai (Salinas, Alicante) & - & 1 & $»$ \\
\hline $\begin{array}{l}6 \text { - Mola Torró (Fuente la Higuera, } \\
\text { Valencia) }\end{array}$ & - & 1 & $»$ \\
\hline 7 - El Tosalet (Bélgida, Valencia) & - & 1 & $»$ \\
\hline $\begin{array}{l}8 \text { - La Bastida de Los Alcuses (Möge, } \\
\text { Valencia) }\end{array}$ & - & 28 & $\gg$ \\
\hline 9 - Cova Foradó (Liria, Valencia) & - & 1 & $\gg$ \\
\hline 0 -Valdegamas (Don Benito, Badajoz) & - & 1 & » \\
\hline
\end{tabular}

Posteriormente, Nordstrom publicou o exemplar de La Esmera (Nordstrom, 1967) e Francisca Hernandez (Hernandez, 1979), o exemplar então ainda inédito do Museu de Cáceres (Fig. 8). Temos poi tanto:

$$
\begin{array}{ll}
11 \text { - La Esmera (San Fulfencio, Alicante) } & -1 \text { exemplar } \\
12 \text { - Villasviejas (Cáceres) } & -1
\end{array}
$$

Dos exemplares portugueses, como já referimos, apenas o de Santa Olaia foi publicado por Santos Rocha. Poderemos atribuir-lhe os números seguintes nesta seriação:

$$
\begin{array}{ll}
13 \text { - Castro de Santa Olaia (Figueira da Foz) } & -1 \text { exemplar } \\
14 \text { - Castro de Segóvia (Eivas) } & -1{ }^{\prime} \\
15 \text { - Cabeço de Vaiamonte (Monforte) } & -1{ }^{\prime \prime} \\
16 \text { - Castro da Azougada (Moura) } & -1{ }^{\prime}
\end{array}
$$

A tipologia de Fletcher Valls (Fletcher Valls, 1957, p. 138) baseia-se essencialmente nas características formais que estes recipientes apresentam, isto é, um corpo cilíndrico, com o bocal 
normalmente localizado sobre o centro do boj o, fechando lateralmente por meio de duas calotes esféricas e apresentando vestigios de terem estado suspensos por meio de um sistema de cordas:

1 - Ban is de bocal central, com caneiuras laterais, sem asas nem patilhas de segurança.

2 - Bairis de bocal central, com caneiuras laterais e patilha de segurança (Vaiamonte ?).

3 - Barris de boca central, com caneiuras laterais e osas sobre as mesmas (Segóvia).

4 - Barris de bocal central com caneiuras sob as asas e estas saindo do próprio bocal (Santa Olaia).

5 - Barris de bocal central, com caneiuras sob as asas e nascendo estas exactamente no bordo do bocal.

6 Barris de bocal descentrado e sem asas.

7 - Barris geminados, muito raros. O único exemplar conhecido é o de La Albufereta (Alicante).

\section{3 - Castro de Santa Olaia (Figueira da Foz) Figs. 1 e 3}

Publicado em 1908 por A. dos Santos Rocha com o número 111 (Ext. XII), cuja reprodução aqui apresentamos (Fig. 1), encontra-se exposto no Museu Municipal Dr. Santos Rocha, naquela cidade (Fig. 2) *.

É constituído por um corpo cilíndrico alongado, encerrado nas suas extremidades por duas calotes esféricas que possivelmente se juntaram posteriormente ao corpo do recipiente, fechando-o. É feito em barro vermelho apresentando vestígios de ter sido pintado a branco. Tem um largo bocal revirado para o exterior, saindo de um gargalo alto, decorado com uma saliência, ou ressalte, paralelo ao bordo em toda a volta, com duas asas implantadas sobre o mesmo e apoiando-se sobre o bojo cilíndrico.

\footnotetext{
* Agradece-se à Dr. ${ }^{a}$ Isabel Pereira, Directora daquele Museu, a autorização para a sua publicação.
} 
Notam-se perfeitamente as estrias paralelas formando caneluras onde passariam as cordas, que, por certo, constituíam um sistema de segurança para o sen transporte, quando cheios de líquido.

Apresenta-se quase completo, embora fragmentado.

Tem as dimensões de $0,70 \mathrm{~m}$ de comprimento por $0,368 \mathrm{~m}$ de altura.

Situamo-lo no número 4 da tipología de Fletcher.

\section{4 - Castro de Segóvia (Elvas), Figs. 3 e 4}

O «barril» do Castro de Segóvia, apesar de fragmentado, permite a sua total reconstituição com excepção do bocal, e foi encontrado durante as escavações de 1972 (Júdice Gamito, 1979, 1980a, 1981), no quadrado B da área A, no estrato correspondente à segunda fase de ocupação do castro, durante a II Idade do Ferro (Fig. 3).

É constituido por um corpo cilíndrico, encerrado por duas calotes esféricas, justapostas a este, e alisadas exteriormente de modo a parecer formar um corpo homogéneo. É feito em barro vermelho com desengordurante relativamente grosso, constituído por grãos de quartzito e mica.

Neste barril pode observar-se o uso da roda em todo o corpo cilíndrico, com excepção das extremidades das calotes esféricas que parecem ter sido fechadas, isto é, coladas à mão, formando um fundo irregular e grosso na parte interna mas perfeitamente alisado exteriormente. O bocal foi certamente estreito como se pode deduzir pelo diâmetro do gargalo, não sendo, porém, possível determinar a sua forma exacta. As duas asas encontram-se implantadas sobre o corpo cilíndrico e afastadas do bocal, vendo-se sob elas as caneluras do sistema de suspensão de cordas, que passavam também pelo bocal, no centro do corpo do barril.

Apresenta-se fragmentado sendo porém possível determinar a sua forma completa.

Tem cerca de $0,44 \mathrm{~m}$ de comprimento por $0,21 \mathrm{~m}$ de altura.

Situamo-lo no número 3 da tipología de Fletcher, lembrando pela forma e tamanho o exemplar de EI Tessalet (Bélgida, Valencia). 


\section{5 - Cabeço de Vaiamonte (Monforte), Figs. 5 e 6}

Este fragmento de «barril ibérico» encontrava-se inédito, nos depósitos do Musen Nacional de Arqueologia e Etnologia, entre os materiais provenientes da escavação que o Prof. Manuel Heleno efectuou naquele cabeço, podendo afirmar-se que foi encontrado no estrato artificial entre $0,50 \mathrm{~m}$ e $0,75 \mathrm{~m}$, juntamente com materiais que apresentam a mesma nota, e que o identificam com um ambiente perfeitamente ibérico.

Este exemplar é constituído por apenas um grande fragmento de um «barril» de barro, com o bocal largo e parte do corpo cilíndrico que o tornam claramente identificável com este tipo de recipiente. Distinguem-se as habituais estrias da roda de oleiro no corpo do vaso e o vestígio de uma canelura por onde passava a corda, na posição envolvente comum a todos estes recipientes (Figs. 5 e 6 ).

É possível que tivesse tido patilhas de segurança laterais, pela inclinação muito acentuada das paredes do corpo cilíndrico junto ao bocal visto que sem elas a fixação das cordas afigura-se-nos bastante difícil. O bocal é largo com o bordo alto levantado (Fig. 6) e abrindo ligeiramente para fora. É feito em barro vermelho comum desengordurante ligeiramente áspero de quartzito.

Este fragmento tem $0,28 \mathrm{~m}$ de comprimento devendo ter pertencido a um recipiente com cerca de $0,55 \mathrm{~m}$ de comprimento total.

Situamo-lo no número 2 da tipologia de Fletcher.

\section{6 - Castro da Azougada (Moura), Fig. 7}

É um fragmento de menores dimensões do que o de \aiamonte mas suficiente para poder ser identificado como tendo pertencido a um «barril ibérico». Também ele se encontrava inédito, no Museu Nacional de Arqueologia e Etnologia, Lisboa, entre os materiais provenientes das escavações que o Professor Manuel Heleno efectuou no Castro da Azougada e que infelizmente permanecem também inéditas. 
É constituido pelo bocal e parte das paredes do corpo cilíndrico, que permitem distinguir os vestigios de roda no corpo do recipiente. $\mathrm{O}$ bocal é largo abrindo ligeiramente para o exterior e tem a decorá-lo um rebordo ligeiro e paralelamente a este uma saliência ou ressalte, em toda a sua volta (Fig. 7). É feito em barro vermelho acastanhado apresentando vestígios de ter sido pintado a branco ou em cor ligeiramente amarela, idêntico nestes aspectos, a pintura e a forma do bordo, ao exemplar de Santa Olaia, mas sem vestígios de asas implantadas no gargalo. É impossível determinar se teria possuído asas ou patilhas de segurança.

Contrariamente ao exemplar anterior e que será discutido seguidamente, no caso da Azougada é impossível acrescentar mais detalhes, inclusivamente sobre a sua possível posição estratigráfica ou a que outros materiais se encontrava associado, por o Prof. Heleno nâo ter publicado estas escavações nem se encontrarem os cadernos de campo ou quaisquer notas elucidativas.

\section{DISCUSSÃO}

Santos Rocha (Santos Rocha, 1908, p. 63) e o próprio Siret (Siret, 1890) consideraram que a origem deste tipo de recipiente estaria certamente localizada no Mediterrâneo oriental, onde surge em Chipre, dominada pelos Fenícios nos séculos vn e vi a.C., e posteriormente também em Cartago, certamente pela mesma via. Fletcher Vails (Fletcher Valls, 1957, p. 140 e s.) embora não recusando esta ideia de puro difusionismo, considera ainda a possibilidade de ser o fruto da evolução local de recipientes idênticos que desde o Neolítico se verificava ocorrerem na região do Levante espanhol. Francisca Hernandez (Hernandez, 1949, p. 461), referindo Fletcher Valls e a possível origem destes vasos no Mediterrâneo Oriental, aceita um difusionismo atenuado, não deixando de salientar o aspecto funcional do recipiente.

Se de facto os contactos com os povos do Mediterrâneo Oriental e de outras zonas deste mar interior são detectáveis desde cedo nesta zona da costa sul da Península Ibérica através de produtos de importação como é o caso do âmbar, dos ovos de avestruz, do marfim ou da concha Spondiliis (Renfrew, 1979, 1967a, 
1967b) o que é certo é que é exactamente aqui que ainda hoje se localiza urna das zonas mais secas da Península, actualmente em avançado grau de desertificação. Por outro lado, tanto a Estremadura espanhola como o Alentejo interior são zonas de elevadas temperaturas estivais acompanhadas de uma secura acentuada do clima. É portanto natural que a resposta do Homem a este ambiente natural tivesse dado origem à concepção de um recipiente facilmente transportável quando envolvido por um sistema de cordas, que permitiria suspendê-lo ao ombro ou no dorso de um animal, aliando, por outro lado, apreciáveis qualidades de frescura e pureza do líquido, que a porosidade do barro permitem. Talvez seja este motivo a razão provável da diversidade de aspecto que os «barris ibéricos» apresentam, e exactamente em La Bastida de los Alcuses, nos arredores de Mogente, Valencia, se terem encontrado 28 exemplares, distribuídos por diversas habitações do povoado.

Os contactos culturais e comerciais entre a zona do Levante espanhol, incluindo o vale do Ebro e o interior do Sudoeste peninsular, foram factos que se verificaram desde o Neolítico e Galcolítico (Schubart, 1980, 1969, 1967) e mais especialmente durante a Idade do Bronze (Schubart, 1975) mas muito particularmente mais tarde no chamado «Período Orientalizante» (Aubet, 1980; Almagro Gorbea, 1977, Cuadrado, 1976). Posteriormente observa-se uma influência mais acentuada destes contactos em plena Idade do Ferro, em que os diferentes grupos étnicos gozavam já de grandes possibilidades de rápida deslocação, vivendo em sociedades complexas dominadoras e belicosas (Júdice Gamito, 1981, 1980b, 1979; Wells, 1980, 1977; Mohen, 1979; Milisauskas, 1978; Clarke, 1972; Morel, 1970; Pellicer, 1969; Schüle, 1969; Wattemberg, 1963; Maluquer de Motes, 1958a e b, 1954) sendo portanto provável que a ideia, aliada aos condicionalismos do meio ambiente, tivesse sido adoptada pelos povos do interior alentejano e das provincias de Badajoz e Cáceres.

Analisando a localização estratigráfica dos exemplares portugueses verificamos que:

1 - No caso do barril de Santa Olaia, embora se encontre referido a um contexto estratigráfico concreto na publicação de 
Santos Rocha (Santos Rocha, 1908, p. 29-31) é-nos impossível determinar a qual dos três povoados da Idade do Ferro, detectados em sobreposição por aquele arqueólogo, pertencerá. $\mathrm{Na}$ verdade, Santos Rocha limita-se a apresentar uma classificação genérica do espolio encontrado no primeiro povoado, afinal o último da Idade do Ferro, imediatamente anterior à ocupação romana, afirmando (p. 29) que se «compõe principalmente de cerámica exótica, pintada ou não, associada a louça indígena de pasta grosseira trabalhada à mão e às vezes com roda, recolhida em todos os os pavimentos das casas e na referida viela». Os tipos são precisamente os mesmos dos povoados inferiores, com raras excepções, não indicando também quais as excepções. $\mathrm{Na}$ análise dos espólios dos povoados imediatamente abaixo, refere apenas que «a cerâmica era idêntica ao do povoado superior».

Assim pode-se afirmai que este barri) foi de facto encontrado numa estratigrafía segura atribuída à II Idade do Ferro, juntamente com outros tipos de cerâmica indígena e de exportação, como ânforas de tipo púnico e pratos de verniz vermelho, datáveis do final do século v ou mesmo do século iv a.C.

2 - O exemplar do Castro de Segóvia é o único que se apresenta integrado numa estratigrafía segura. Foi encontrado no quadrado $\mathrm{B}$, da área $\mathrm{A}$, das escavações efectuadas em 1972, no estrato correspondente ao segundo nível de ocupação do castro (Fig. 3) onde se observa a predominância de cerâmica decorada com cordões de incisões e dedadas, ainda a ocorrência de cerâmica estampilhada com largas matrizes rectangulares de tipo hallstáttico final e outras mais leves, já com estilizações de tipo La Tène (Schwappach, 1976, 1969; Jacobstahl, 1969) e cerâmica cinzento-negro brunida, cerâmicas estas na continuação do estrato anterior, com a introdução de cerâmicas pintadas com faixas paralelas, decoração tipicamente «ibérica». Este estrato datável entre o século veo século iv a.C. apresenta-se especialmente evidente nos quadrados $\mathrm{A}$ e $\mathrm{B}$, em que é perfeitamente visível um pavimento de argila a separá-lo do estrato anterior, e que também aparece nitidamente na muralha do corte $\mathrm{Al}$, no prolongamento do quadrado A. 
Tal como o exemplar de Villasviejas (Hernandez, 1979) também o do Castro de Segóvia foi encontrado numa área de habitação, cujo traçado rectangular se prolonga pelo quadrado A (Júdice Gamito, 1980a, 1979). Os materiais com que se acha associado identificam-no com idêntico horizonte cultural: vasos de cerámica negra, ou de faixas pintadas paralelamente umas às outras, ou as mesmas faixas sobre brunido interno e externo, características da época de pleno desenvolvimento da cultura «ibérica».

$3-\mathrm{O}$ exemplar de Vaiamonte, embora sem estratigrafía definida, tem como elemento identificativo quanto à sua localização estratigráfica a nota a lápis, atrás mencionada, situando-o no estrato artificial entre 0,50 e $0,75 \mathrm{~m}$. Outros fragmentos de cerâmica decorados com faixas pintadas paralelas, e cerâmicas brunidas de cor cinzento-negro, portadoras de idêntica nota, permitem-nos considerá-lo como parte integrante de um horizonte cultural «ibérico», que é ainda reforçado pela presença, neste mesmo estrato, de fíbulas de apêndice caudal de tipo transmontano (da Ponte, 1980; Santos, 1973) e que tornam este estrato artificial datável entre o século veo século iv a.C.

Parece-nos assim que se confirma nos exemplares portugueses a cronologia atribuída pelos investigadores espanhóis para este tipo de recipiente, isto é, o século iv, com possibilidade de se poder recuar um pouco esta data para o século $\mathrm{V}$ em alguns casos, e excepcionalmente para o do barril de Valdegamas, que Blanco Freijeiro atribuiu a data anterior à primeira metade do século vi a.C. (Blanco, 1953). Não nos parece que a qualquer dos exemplares portugueses se possa atribuir uma data tão recuada.

Os contextos em que foram encontrados caracterizam-se, na realidade, por uma acentuada uniformidade cultural num horizonte que se considerou denominar de «ibérico» pelas suas características específicas na Península Ibérica a partir do século v a.C. E natural, por outro lado, que se tenham estabelecido contactos importantes e frequentes entre o Levante espanhol $\mathrm{e}$ as áreas interiores do Sudoeste, facto detectável também na ocorrência de outros tipos de cerâmica, nomeadamente a Ática (Rouillard, 1975; Cuadrado, 1974; Blazquez, 1975). 
Os «barris ibéricos» poderiam ter adquirido a sua forma básica comum, tão característica, através do contacto entre estas duas áreas principais, mas a variedade dos diferentes recipientes é tão grande, que nos parecem ser os testemunhos de criações locais independentes, respondendo muito provavelmente a necessidades semelhantes resultantes de ambientes igualmente secos e quentes, sendo de salientar ainda a sua ocorrência em contextos coerentes característicos da chamada 'cultura ibérica' datáveis dos séculos v e iv a.C.

\section{BIBLIOGRAFIA}

Almagro Gorbea, M., $1977-E l$ Bronce Final y el Periodo Orientalizante en Extremadura, B.P.H., Madrid.

AU BE T, M. ${ }^{a}$ E., $1980-$ Los Marfiles Fenicios del Bajo Guadalquivir, in B.S.A.A., Salamanca.

Ballester Tormo, L, y Pericot Garcia, L., 1928 - La Bastida de los Alcuses (Mogente), in Arch. Prehist. Leo., Valencia.

BLANCO FreiJeIro, A., 1953 - El Vaso de Valdegamas (Don Benito, Badajoz) y outros Vasos del Mediodia Español, in Arch. Esp. Arq., Madrid.

CLAR KE, D. L., 1972 - Models in Archaeology, London.

CUADRADo, E., 1972 - Tipologia de la Cerámica Ibérica Fina de «El Cigarralejo», Muía (Murcia), in Trab. de Prehist., v. 29, Madrid.

-_._, 1974 - Penetración de las Influencias Colonizadoras Greco-Fenicias en el Interior Peninsular, in Symposio de Colonizaciones, Barcelona.

DeChelette, J., 1914 - Manuel d'Archéologie Prehistorique Celtique et Gallo-Bomaine, v. II, 2éme Partie, París.

Fernendez de Aviles, A., 1942 - Tonel Ibérico del Castillico de La Peñas, in Arch. Esp. Arq., Madrid.

Fletcher VAlls, D., 1957 - Toneles Cerámicos Ibéricos, in Arch. Prehist. Leo., Valencia.

Furgus, P. J., 1937 - Colleció de Trabalis sobre Prehistoria Valenciana, in Serie de Trabajos Vários del Sero. de Ino. Prehist., Valencia.

Hernandez, F., H., $1979-$ Tonel Ibérico Procedente del Castro de Villasviejas, in Trab. de Prehist., n. 36, Madrid.

J A C O B S T H A L, P., 1969 - Early Celtic Art., Oxford.

JÚdice Gamito, T., 1979 - Aspects of Settlement, Economy and Society in Southern Portugal from 600 B. C. till the Boman Conquest, Cambridge.

---, 1980a - Aspectos da Idade do Ferro no Sul de Portugal: o Povoamento e a economia, in Actas do IV Cong. Nac. de Arq. (Faro), no prelo.

Conimbriga, 22 (1983), 195-208 
--- 1980b - A situação estratégica do Castro de Segóvia e a Romanizaçâo,

in Actas do IV Cong. Nac. de Arq. (Faro), no prelo.

, 1981 - Resistência a Roma no Sudoeste Peninsular, in Historia, n. 29, Lisboa.

--_-_, 1982 - Breve Nota Sobre as Escavações do Castro de Segóvia - 1981,

in A Cidade, Portalegre.

Maluquer De Motes, $1954-$ El Yacimiento Hallstattico de Cortes de Navarra, I, Pamplona.

$-{ }_{5} 1958$ - El Barrueco, Las excavaciones Arq. en el Cerro del Barrueco, Salamanca.

-_._- $1958 \mathrm{~b}$ - Las Cogotas,

MILIS A US KAS, S. 1978 - European Prehistory, New York.

Mонеn, J.-P., 1979 -La Présence Celtique de La Téne dans le Sud-Ouest de L'Europe: Indices Archéologiques, in Colloque International des Movements Céltiques, Paris.

Morel, J. P., 1970 - Les Phocéans dans L'Extreme Occident, vus depuis Tartessos, in Parola del Passato, Ñapóles.

^^1975 - 1975 - L'Expansion Phocéerine en Occident, in Bulletin de Correspondence Hellenique, n. 99.

Nordstrom, S., 1967 - Excavaciones en el Poblado Ibérico de La Escuera, San Fulgencio, Alicante, Serv. Inv. Prehist. Valencia.

Pellicer, M., 1969 - Las Primeras Cerámicas a Torno Pintadas Andaluzas y sus Problemas, V Simp. O. P., Barcelona.

DA Ponte, M. ${ }^{a}$ S., $1980-A$ Génese das Fíbulas do Noroeste Peninsular, in Actas do Sem. de Arq. do Noroeste Peninsular, Guimarães.

RENFREW, C., 1967a - Colonialism and Megalithismus, in Antiquity, XLI.

1967b - Cycladic Metallurgy and the Aegean Early Bronze Age, in Amer. Journal of Arch., 71.

- 1979 - Problems in European Prehistory, Edinburgh.

Rouillard, P., 1975 - Les Coupes Attiques à Figures Rouges du IVe S. en Andalusie, in Melanges de la Casa de Velazquez, Tome XI, Paris.

SANTOS, M., F., 1973 - Fibulas Recolhidas no Cabeço de Vaiamonte, in Anais, n. ${ }^{\circ} 22$, Lisboa.

SCHÜLE, W., 1969 - Die Meseta-Kulturen der Iberischen Halbinsel, M. M., Madrid.

SCHUBART, H., 1969 - Las Fortificaciones Eneolíticas de Zambujal y Pedra do Ouro en Portugal, in X Cong. Nac. Arq., Menorca.

--_--, 1975 - Les Ibères.

-__-_, 1975 - Die Kultur der Bronzezeit im Sïdwtsten der Iberisdhen Halbinsel, M. F., Berlin.

---, 1981, Zambujal, M. F., Berlin.

SCHWAFPACH, F., $1969-$ Stempelverzierte Keramik von Armorica, Fundbericht aus Hessen, Beiheft 1 .

--_--, 1976, L'Art du «Premier Style» Celtique, in Celtic Art in Ancient Europe, London,

Conimbriga, 22 (1983), 195-208 
SIRET, L., 1893 - L'Espagne Prehistorique, in Revue des Questions Scientifiques.

TRUMP, D. H. - The Prehistory of the Mediterrenean, London.

WATTEM ВеRG, $\mathrm{F}_{5} 1963$-Las Cerámicas Indigenas de Numancia, Valladollid.

Wells, P., 1977 - Late Hallstatt Interaction with the Mediterranean: one suggestion, in Ancient Europe and the Mediterranean, Warminster. -, 1980 - Culture Contact and Culture Change, Cambridge. 


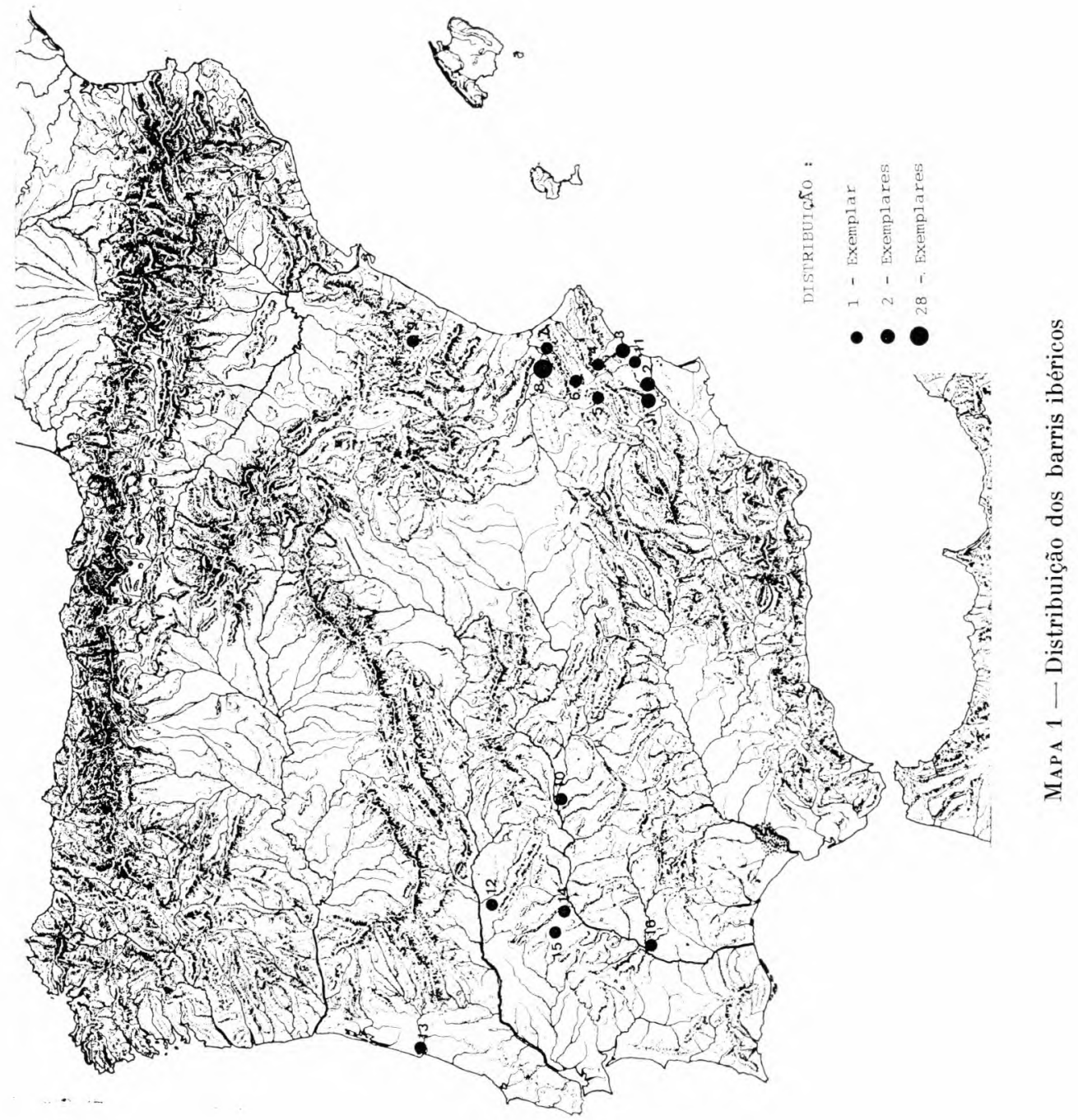



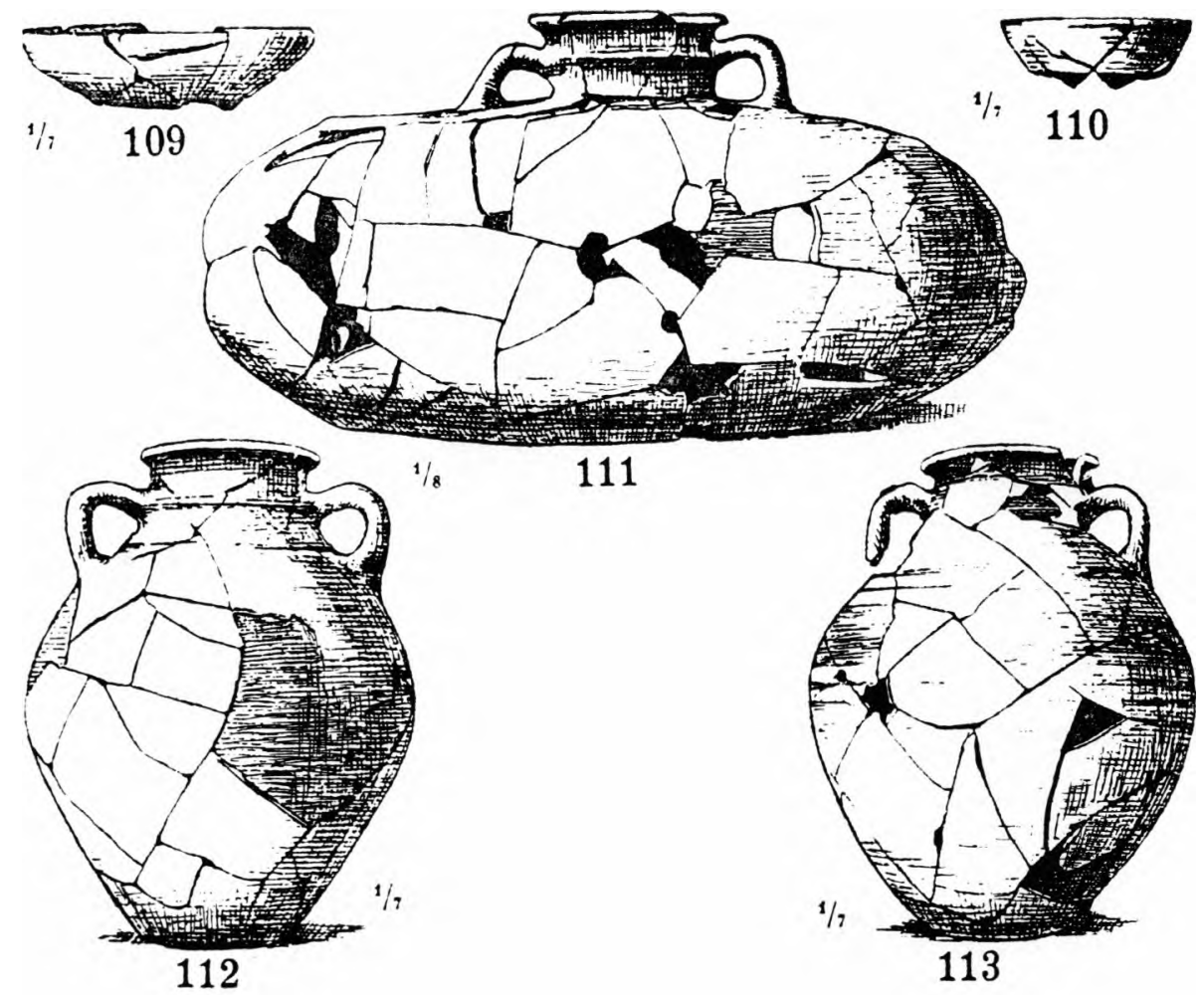

DA ESTAÇÃo PRÉ-ROMANA DE SANTA OLAIA

FIg. 1 - Reprodução da estampa xıI da publicação de Santos Rocha 


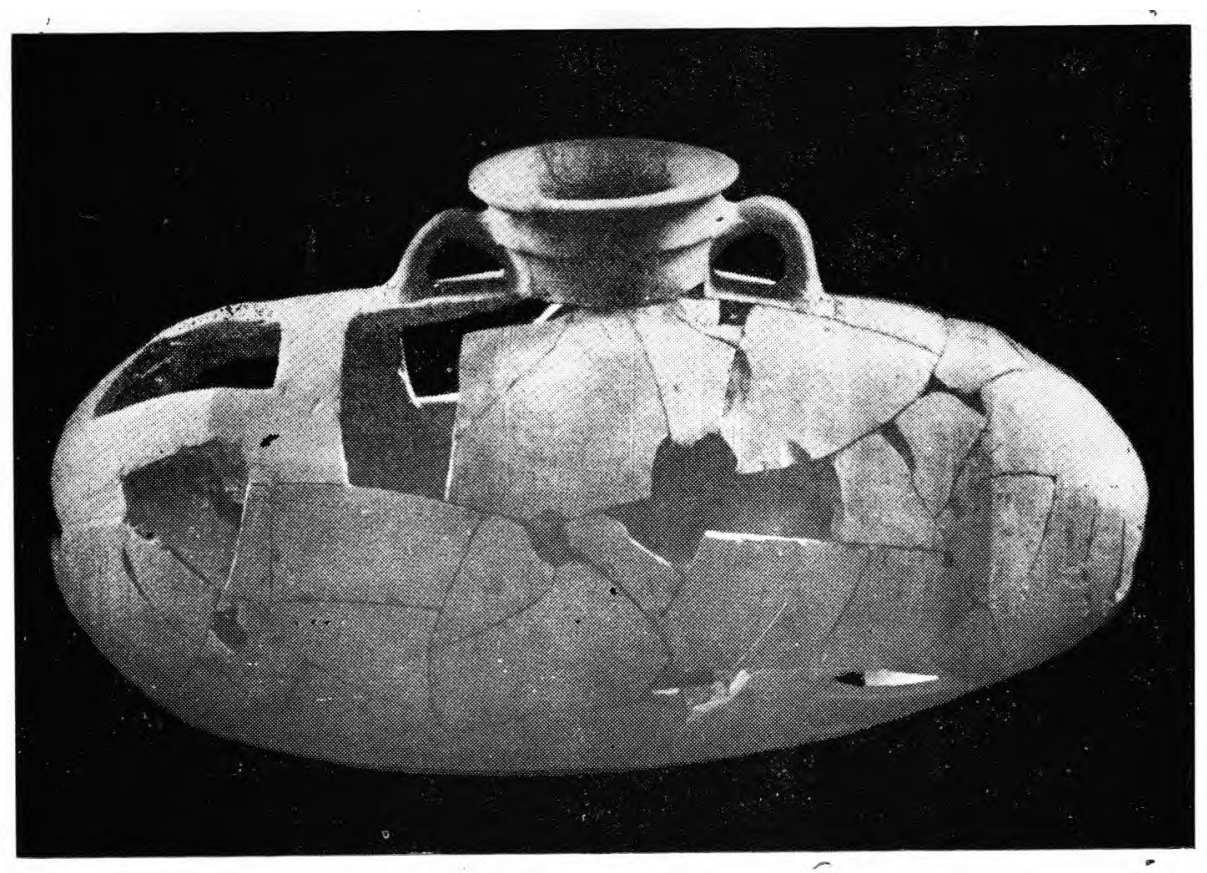

Fig. 2 - O barril de Santa Olaia, tal como se encontra exposto no Museu Municipal Dr. Santos Rocha, na Figueira da Foz (Fotografia gentilmente cedida pela Directora daquele Museu) 


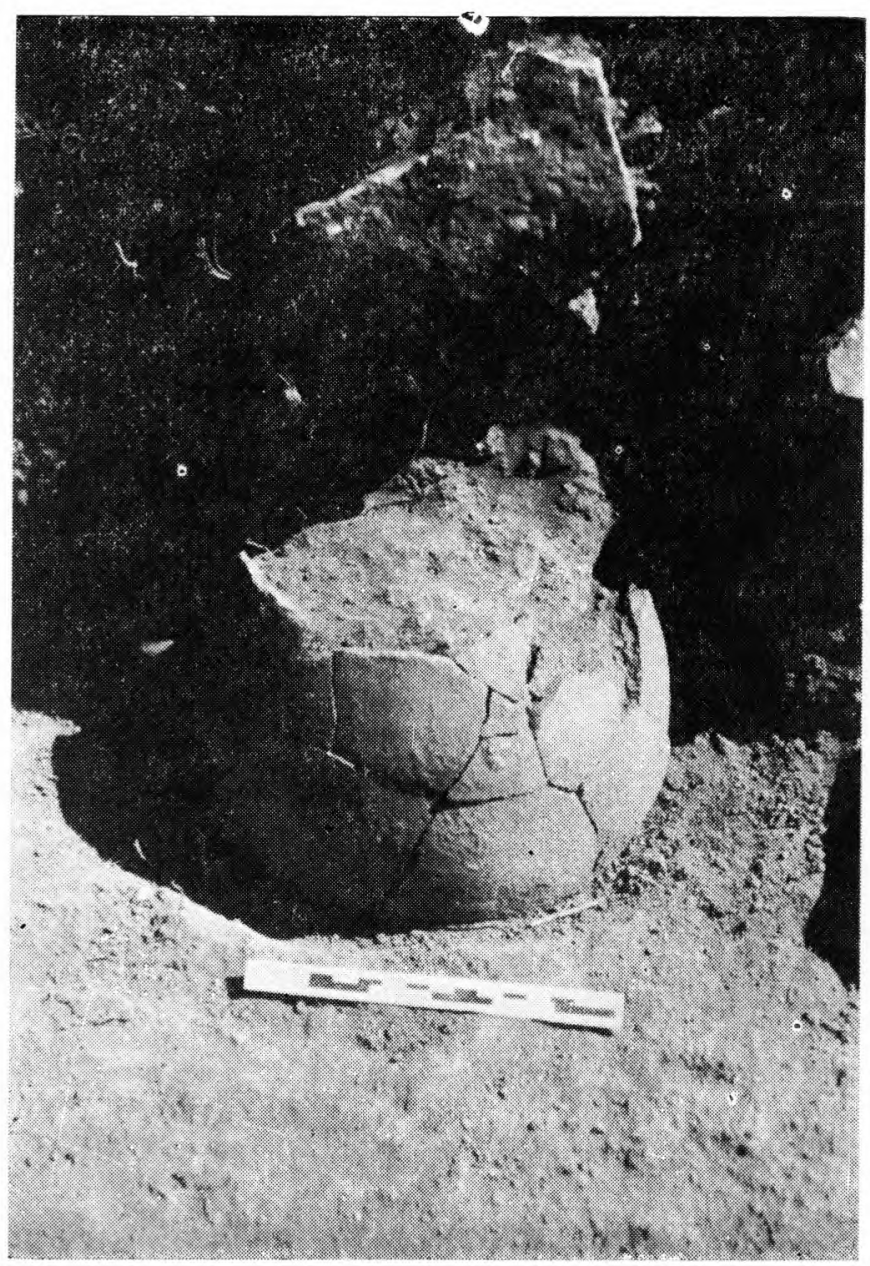

FIg. 3 - O barril do Castro de Segóvia tal como foi encontrado no estrato 5, do quadrado B, da área A (Escavações de 1972) 


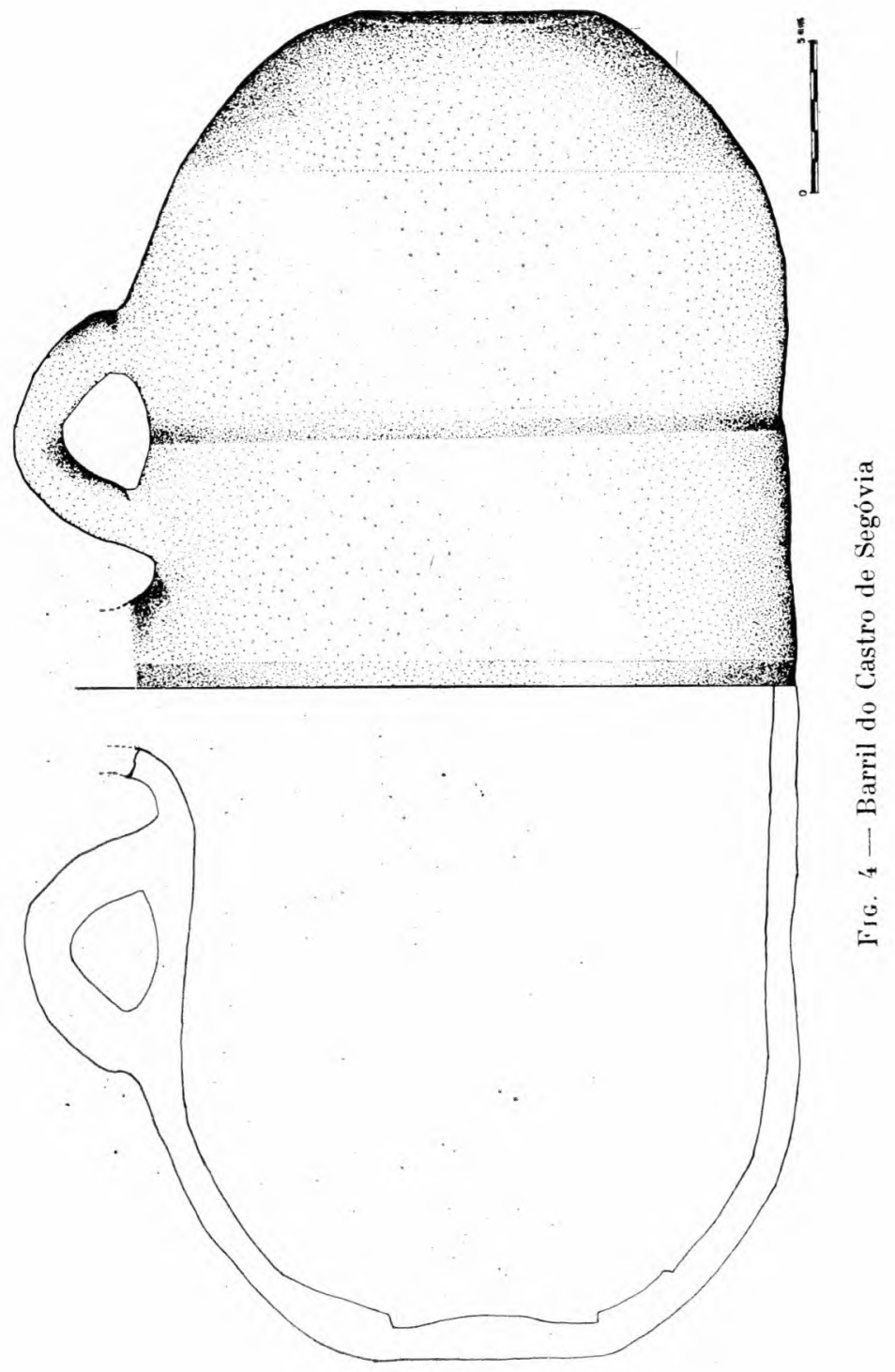




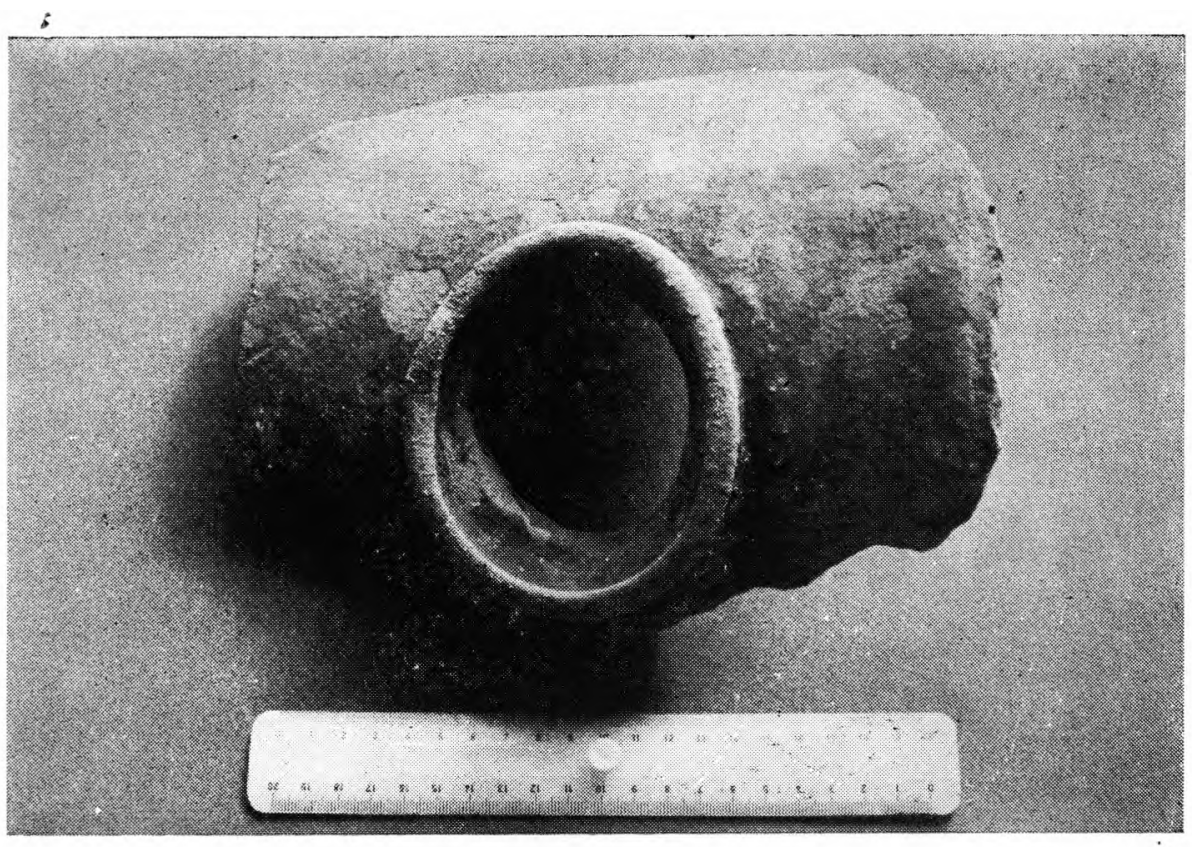

Fig. 5 - O fragmento do barril do Cabeço de Vaiamonte, parte das colecçōes do Museu Nacional de Arqueologia e Etnologia, em Lisboa 


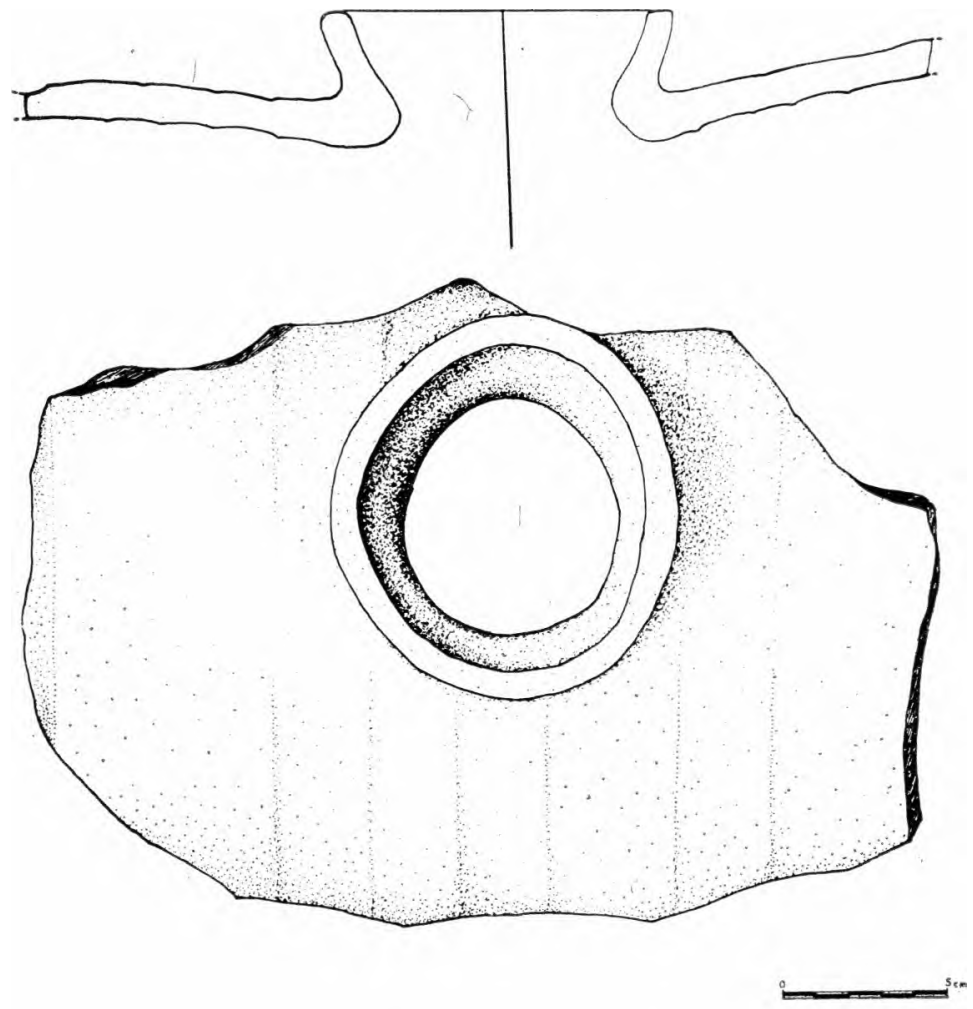

FIG. 6-Barril de Vaiamonte (Monforte) 

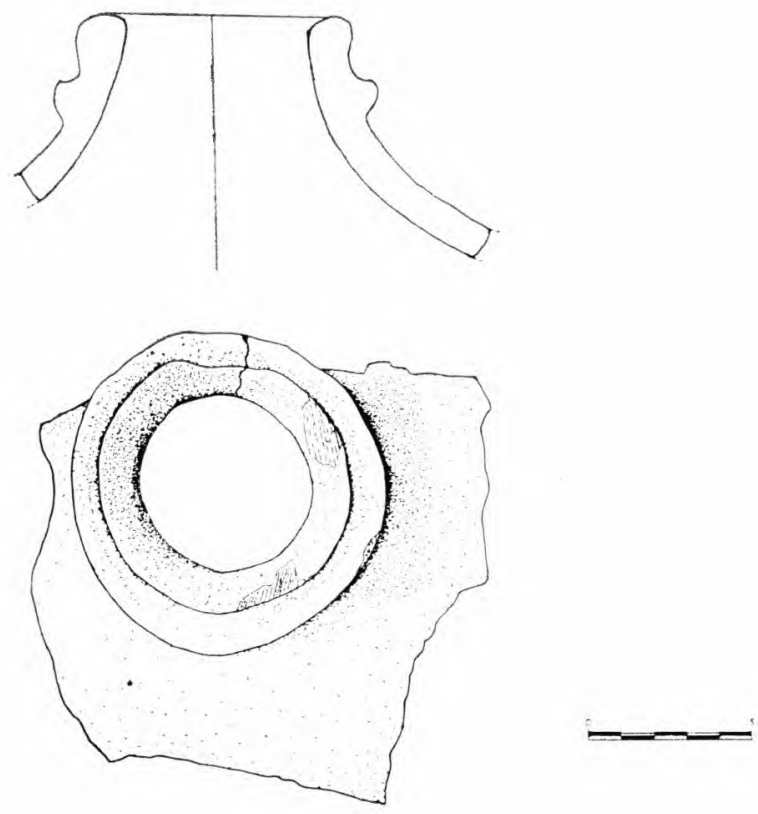

Fig. 7 - Barril de Azougada (Moura)

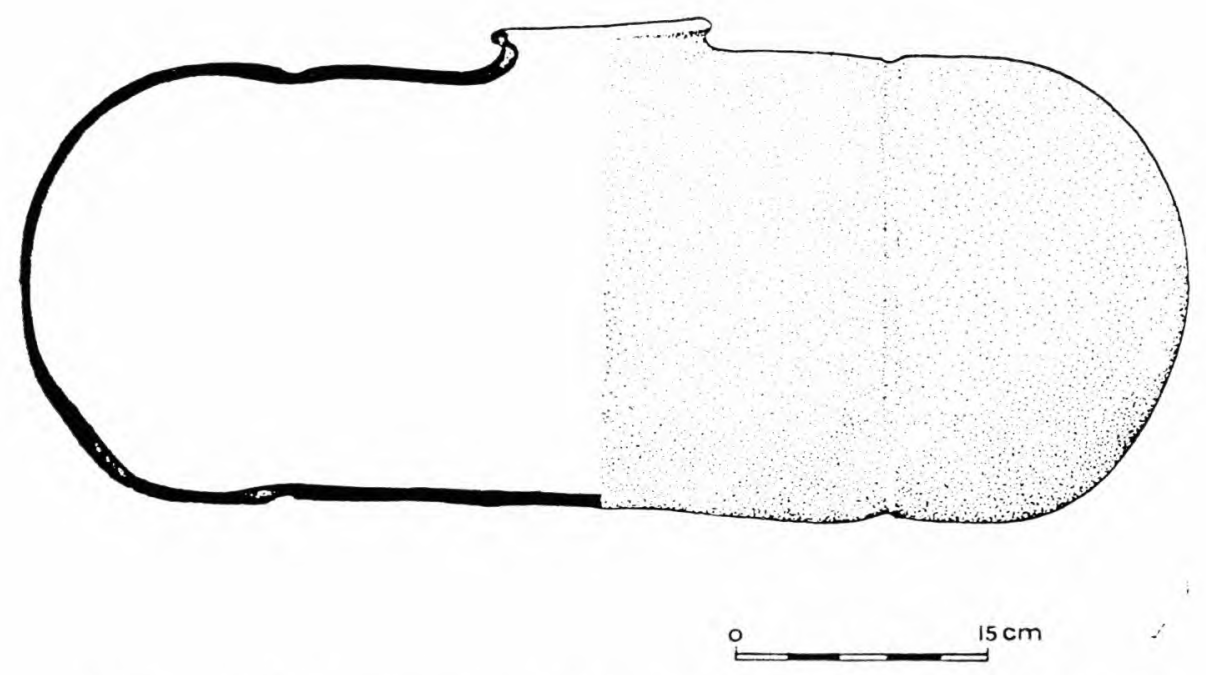

Fig. 8-O Barril de Villasviejas tal como foi publicado por F. Hernandez 